\title{
Duration of new antidepressant use and factors associated with discontinuation among community-dwelling persons with Alzheimer's disease
}

\author{
Reetta Kettunen $^{1} \cdot$ Heidi Taipale ${ }^{1,2,3}$ (D) Anna-Maija Tolppanen ${ }^{1,4}$ - Antti Tanskanen ${ }^{3,5,6}$ Jari Tiihonen $^{3,5}$. \\ Sirpa Hartikainen ${ }^{1,2}$ - Marjaana Koponen ${ }^{1,2}$
}

Received: 8 August 2018 / Accepted: 29 October 2018 / Published online: 9 November 2018

(C) The Author(s) 2018

\begin{abstract}
Purpose To study how long antidepressants initiated after diagnoses of Alzheimer's disease (AD) were used and factors associated with discontinuation of use among persons with Alzheimer's disease (AD). In addition, differences in duration of use between the antidepressants groups were compared.

Methods Register-based Medication use and Alzheimer's disease (MEDALZ) cohort included 70,718 community-dwelling people with AD who were diagnosed during the years 2005-2011. For this study, the new antidepressant users were included after 1-year washout period $(N=16,501 ; 68.6 \%$ females, mean age 80.9$)$. The duration of antidepressant use was modeled with the PRE2DUP method. Factors associated with treatment discontinuation were assessed with Cox proportional hazard models and included age, gender, comorbid conditions and concomitant medications.

Results Median duration of the new antidepressant use period was 309 days (IQR 93-830). For selective serotonin reuptake inhibitor (SSRI) use, the median duration was 331 days (IQR 101-829), for mirtazapine 202 days (IQR 52-635), and for serotonin and norepinephrine reuptake inhibitors (SNRIs) 134 days (IQR 37-522). After 1-year follow-up, 40.8\% had discontinued antidepressant use, $54.6 \%$ after 2 years and $64.1 \%$ after 3 years. Factors associated with treatment discontinuation were age over 85 , male gender, diabetes, and use of memantine, opioids, and antiepileptics whereas benzodiazepines and related drugs and antipsychotic use were inversely associated with discontinuation.

Conclusions Antidepressants are used for long-term among people with AD. Need and indication for antidepressant use should be assessed regularly as evidence on their efficacy for behavioral and psychological symptoms of dementia is limited.
\end{abstract}

Keywords Antidepressants · Alzheimer's disease · Dementia · Drug utilization · Discontinuation $\cdot$ Persistence

Electronic supplementary material The online version of this article (https://doi.org/10.1007/s00228-018-2591-5) contains supplementary material, which is available to authorized users.

Heidi Taipale

heidi.taipale@uef.fi

1 School of Pharmacy, University of Eastern Finland, PO Box 1627, 70211 Kuopio, Finland

2 Kuopio Research Centre of Geriatric Care, University of Eastern Finland, PO Box 1627, 70211 Kuopio, Finland

3 Department of Clinical Neuroscience, Karolinska Institutet, Tomtebodavägen 18A, 5th floor, 17177 Stockholm, Sweden
4 Research Centre for Comparative Effectiveness and Patient Safety (RECEPS), University of Eastern Finland, PO Box 1627, 70211 Kuopio, Finland

5 Department of Forensic Psychiatry, Niuvanniemi Hospital, University of Eastern Finland, Kuopio, Finland

6 Public Health Evaluation and Projection, National Institute for Health and Welfare, PO Box 30, FI-00271 Helsinki, Finland 


\section{Introduction}

Over the last two decades, prevalence of antidepressant use has increased and treatment duration has prolonged in older people [1]. Antidepressants are frequently used also among people with Alzheimer's disease (AD), with annual prevalence of use of 28 $31 \%$ reported in previous studies [2-4]. Main indications for antidepressant use are depression and anxiety disorders [5]. However, these drugs are also used for other indications such as neuropathic pain, insomnia, and migraine. Among persons with $\mathrm{AD}$, antidepressants are used for treatment of behavioral and psychological symptoms of dementia (BPSD) although their effectiveness in this indication is modest $[6,7]$.

Antidepressant use is also associated with an increased risk of adverse effects and events, such as falls, fractures, cardiovascular events, all-cause mortality, and upper gastrointestinal bleeding among older persons $[8,9]$. Clinically significant drug-drug interactions with antidepressants are also possible, especially among older persons using multiple concomitant drugs [10]. Among vulnerable people with cognitive disorders, the risk of adverse drug events is less studied. Among people with $\mathrm{AD}$, antidepressant use has been associated with an increased risk of hip fractures and head injuries, and the risks remained elevated in long-term use [11, 12]. In addition, use of citalopram among people with $\mathrm{AD}$ has been associated with worsening of cognition and QT interval prolongation compared with placebo [13]. Discontinuation of antidepressant use may also be problematic as withdrawal symptoms may emerge [14].

The duration of antidepressant use has been previously investigated among general older population [15-17] and among people with dementia [18] whereas the studies among community-dwelling persons with AD are lacking. Previous studies have found a median duration of use 64 days [17] and 175 days [15] and mean duration of 266 days [16]. One study among general older people [15] and another among persons with dementia [18] also investigated factors associated with treatment discontinuation and found varying results. We studied how long antidepressants initiated after AD diagnosis among community-dwelling persons with $\mathrm{AD}$ were used, which factors were associated with discontinuation and differences in the duration of use between the antidepressants groups.

\section{Materials and methods}

This study was a part of the register-based MEDALZ study including 70,718 people who received clinically verified diagnosis of AD during the years 2005-2011 in Finland. The diagnoses of $\mathrm{AD}$ were identified from the special reimbursement register, as described previously in detail [19]. Diagnoses of AD was according to NINCDS-ADRDA [20] and DSM-IV criteria, and the diagnoses were verified by geriatrician or neurologist. Data from several nationwide registers included the prescription register (1995-2015), the special reimbursement register (1972-2015), and the hospital discharge register (1972-2015). MEDALZ also contains socioeconomic data (1972-2015) and causes of death (2005-2015) from the Statistics Finland (see details in Supplementary material).

Antidepressant use was identified by Anatomical Therapeutic Chemical (ATC) codes N06A from the prescription register data. Antidepressants were further categorized as tricyclic antidepressants (TCAs; N06AA), selective serotonin reuptake inhibitors (SSRIs; N06AB), mirtazapine (N06AX11), and serotonin and norepinephrine reuptake inhibitor (SNRIs) including venlafaxine (N06AX16), milnacipran (N06AX17), and duloxetine (N06AX21). Other antidepressants were grouped together (described in Supplementary material). Due to small number of users, TCAs were combined into group of other antidepressants. Indication of drug use is not recorded in the registers utilized in this study. The duration of antidepressant use was modeled with the PRE2DUP method [21]. It is based on calculation of sliding averages of defined daily doses (DDDs) according to individual drug use patterns. Each ATC code for each person is modeled separately and by considering hospital care periods (as drugs used during hospital care are not recorded in the register), stockpiling of drugs, variation in purchase events, and changing dose. Duration of "any antidepressant" use was derived by combining overlapping drug use periods of all specific antidepressant substances. Modeling time on the antidepressant groups (SSRIs and SNRIs) were constructed similarly, by considering those specific groups only.

Persons who initiated antidepressants after AD diagnosis were identified $(n=24,922)$. One-year washout period before the first antidepressant purchase was used to exclude prevalent users $(n=6387)$. In addition, the antidepressant users at the date of $\mathrm{AD}$ diagnosis were excluded $(n=1032)$. Due to lack of the medication information during hospital care, we excluded users who were in hospital care over half of the washout period or having long (>90 days) ongoing hospitalization/ institutionalization at the end of washout period $(n=$ 842). Finally, 160 antidepressant initiators who were in hospital care during the entire study period were excluded. The final study sample included 16,501 new initiators of antidepressants.

The follow-up began from the first antidepressant purchase after $\mathrm{AD}$ diagnosis. The follow-up ended for following reasons (whichever came first): long hospital/ institutional stay (>90 days), death, end of study period (December 31, 2015), after 4 years of follow-up or discontinuation of antidepressant use. In drug group-specific analyses, the follow-up was also 
censored at switch to, or concomitant use of the different antidepressant groups. Discontinuation of antidepressant use was considered as an outcome event in the analyses.

\section{Covariates}

Comorbidities were identified from the special reimbursement register as diagnosed before the antidepressant initiation. Cardiovascular diseases included chronic heart failure, hypertension, coronary artery disease, and chronic arrhythmias. Data on asthma/chronic obstructive pulmonary disease (COPD), diabetes, glaucoma, rheumatoid arthritis, and epilepsy were collected similarly. Hospital discharge register comprised hospital care periods with discharge diagnoses, categorized according to ICD-10 classification (with the corresponding ICD-8 and ICD9 codes). Comorbidities from the hospital discharge register included histories of stroke, fracture, schizophrenia, depression, and bipolar disorder. Schizophrenia, depression, and bipolar disorder were considered if they were diagnosed at least 5 years before $\mathrm{AD}$ diagnoses. Active cancer was defined within 1 year before antidepressant initiation as cancer treated in hospital care, or use of antineoplastic drugs (definitions provided in Supplementary material).

Use of other drugs was measured during the 183 days (later 6 months) before the antidepressant initiation. Acetylcholinesterase inhibitor (AChEI), memantine, nonsteroidal anti-inflammatory drugs (NSAIDs), paracetamol, opioids, antiepileptics, antipsychotics and benzodiazepines, and related drugs were included. Previous antidepressant use was defined as antidepressant use before the washout.

\section{Statistical analysis}

Descriptive statistics comparing the users of antidepressant classes were conducted with chi-squared tests for categorical variables. Duration of antidepressant use was described with median and interquartile ranges (IQRs). As duration of use is also affected by the end of follow-up, we also analyzed median time to discontinuation by Kaplan-Meier. The first discontinuation analysis included all new antidepressant users, with censoring to long hospital stay ( $>90$ days), death, after 4 years of use and the end of study period (December 31, 2015). The second analysis included three different antidepressant groups (SSRIs, SNRIs, and mirtazapine), with censoring to change of drug group and concomitant use of these groups, in addition to censoring events described for the first analyses. SSRIs, SNRIs, and mirtazapine were the three major groups covering $97.4 \%$ of all users. Initiators of TCAs and other antidepressants or combinations were not analyzed separately due to low number of users.

Cox regression analysis was used to investigate factors associated with discontinuation of the antidepressant use. Hazard ratios (HRs) were calculated with $95 \%$ confidence intervals (CIs). The analyses were adjusted for the following factors: gender, age $(<75,75-84, \geq 85)$, cardiovascular disease, history of stroke, diabetes, asthma/COPD, glaucoma, active cancer, rheumatoid arthritis, epilepsy, schizophrenia, depression or bipolar disorder, previous fracture, substance abuse, and use of AChEI, memantine, opioids, NSAIDs, paracetamol, BZDR, antipsychotics, antiepileptics, and previous antidepressant use.

All analysis were performed using IBM SPSS Statistics for Windows, Version 24.0. Armonk, NY: IBM Corp.

\section{Ethics of the study}

Data were retrieved from the registers by the register maintainers and de-identified register data were submitted to the research team. According to Finnish legislation, no ethics committee approval is required as participants were not contacted in any way.

\section{Results}

Among new users of antidepressants, $68.6 \%$ were female and mean age at the time of antidepressant initiation was 80.9 years (SD 7.0) (Table 1). The median time from the diagnosis to initiation of antidepressant use was 570 days (IQR $=205$ 1150). SSRIs were most commonly initiated antidepressant group, $n=9047(54.8 \%)$, citalopram $(n=4426)$, and escitalopram $(n=4110)$ in most cases, followed by mirtazapine, $n=6462(39.2 \%)$. Compared to others, SNRI users had more frequently rheumatoid arthritis and previous fracture. In addition, SNRI users used more often analgesics, antiepileptics, and memantine at the baseline and had history of antidepressant use. At baseline, mirtazapine users used more often BZDRs and antipsychotics compared with the other antidepressant users.

Most of the antidepressant users (76.8\%) had only one antidepressant use period during the follow-up. Among those who reinitiated use, the median time between the first and the second period was 120 days (IQR $=56-295$ ). Median duration of the first antidepressant period was 309 days (IQR 93-830) (Table 2). SSRI users had the longest duration of use (median 331 days), followed by mirtazapine users (202 days) and SNRI users (134 days). Durations less than 1 month were more frequently observed for SNRI users and mirtazapine users. SSRI users were more likely to use over 4 years $(10.1 \%)$ whereas SNRI users were least likely $(4.8 \%)$.

The most common reason for end of the antidepressant use was treatment discontinuation in all drug groups (Table 2). Figure 1a presents continuation of antidepressant use in relation to time since initiation of use. The median time to treatment discontinuation was 588 days (95\% CI 564-612) and 
Table 1 Baseline characteristics of new antidepressant users and differences between the antidepressant groups (selective serotonin reuptake inhibitors [SSRI], mirtazapine and serotonin and norepinephrine reuptake inhibitor [SNRI] users compared with chi squared test)

\begin{tabular}{|c|c|c|c|c|c|}
\hline Characteristics & New users $n=16,501$ & SSRI $n=9047$ & Mirtazapine $n=6462$ & SNRI $n=557$ & $p$ value* \\
\hline Female, $n(\%)$ & $11,320(68.6)$ & $6355(70.2)$ & $4283(66.3)$ & 409 (73.4) & $<0.001$ \\
\hline \multicolumn{5}{|l|}{ Age at the time of initiation, $n(\%)$} & \multirow[t]{4}{*}{$<0.001$} \\
\hline$<75$ & $2671(16.2)$ & $1594(17.6)$ & $905(14.0)$ & $90(16.2)$ & \\
\hline $75-84$ & $8571(51.9)$ & $4748(52.5)$ & $3295(51.0)$ & $289(51.9)$ & \\
\hline$\geq 85$ & $5259(31.9)$ & $2705(29.9)$ & $2262(35.0)$ & $178(32.0)$ & \\
\hline \multicolumn{5}{|c|}{ Time from Alzheimer's disease diagnosis to antidepressant use, $n(\%)$} & \multirow[t]{6}{*}{$<0.001$} \\
\hline$<6$ months & $3721(22.6)$ & $2151(23.8)$ & $1369(21.2)$ & $108(19.4)$ & \\
\hline 6-12 months & $2499(15.1)$ & $1457(16.1)$ & $893(13.8)$ & $83(14.9)$ & \\
\hline 12-24 months & $3386(20.5)$ & $1938(21.4)$ & $1220(18.9)$ & $122(21.9)$ & \\
\hline $24-48$ months & $4227(25.6)$ & $2251(24.9)$ & $1713(26.5)$ & $153(27.5)$ & \\
\hline Over 48 months & $2668(16.2)$ & $1250(13.8)$ & $1267(19.6)$ & $91(16.3)$ & \\
\hline \multicolumn{6}{|l|}{ Comorbidities, $n(\%)$} \\
\hline Cardiovascular disease & $8335(50.5)$ & $4461(49.3)$ & $3365(52.1)$ & $284(51.0)$ & 0.003 \\
\hline History of stroke & $1733(10.5)$ & $931(10.3)$ & $682(10.6)$ & $62(11.1)$ & 0.746 \\
\hline Diabetes & $2194(13.3)$ & $1170(12.9)$ & $876(13.6)$ & $76(13.6)$ & 0.503 \\
\hline Asthma/COPD & $1466(8.9)$ & $754(8.3)$ & $619(9.6)$ & $13(6.6)$ & 0.017 \\
\hline Glaucoma & $1572(9.5)$ & $861(9.5)$ & $616(9.5)$ & $58(10.4)$ & 0.781 \\
\hline Active cancer & $663(4.0)$ & $361(4.0)$ & $253(3.9)$ & $24(4.3)$ & 0.892 \\
\hline Rheumatoid arthritis & $706(4.3)$ & $376(4.2)$ & $268(4.1)$ & $41(7.4)$ & 0.001 \\
\hline Epilepsy & $368(2.2)$ & $194(2.1)$ & $149(2.3)$ & $14(2.5)$ & 0.713 \\
\hline History of schizophrenia & $192(1.2)$ & $95(1.1)$ & $83(1.3)$ & $8(1.4)$ & 0.333 \\
\hline History of depression or bipolar disorder & $424(2.6)$ & $219(2.4)$ & $171(2.6)$ & $18(3.2)$ & 0.388 \\
\hline Previous fracture & $3959(24.0)$ & $2039(22.5)$ & $1665(25.8)$ & $157(28.2)$ & $<0.001$ \\
\hline Substance abuse & $452(2.7)$ & $213(2.4)$ & $214(3.3)$ & $15(2.7)$ & 0.002 \\
\hline \multicolumn{6}{|c|}{ Use of other drugs 6 months before antidepressant initiation, $n(\%)$} \\
\hline \multicolumn{6}{|c|}{ Alzheimer's disease medication } \\
\hline AChEI & $10,979(66.5)$ & $6061(67.0)$ & $4266(66.0)$ & $346(62.1)$ & 0.040 \\
\hline Memantine & $6312(38.3)$ & $3380(37.4)$ & $2563(39.7)$ & $229(41.1)$ & 0.006 \\
\hline \multicolumn{6}{|l|}{ Analgesics } \\
\hline Opioids & $1963(11.9)$ & $834(9.2)$ & $874(13.5)$ & $168(30.2)$ & $<0.001$ \\
\hline NSAIDs & $2165(13.1)$ & $1181(13.1)$ & $781(12.1)$ & $104(18.7)$ & $<0.001$ \\
\hline Paracetamol & $5909(35.8)$ & $2899(32.0)$ & $2559(39.6)$ & $280(50.3)$ & $<0.001$ \\
\hline \multicolumn{6}{|l|}{ Psychotropic drugs } \\
\hline BZDR & $5869(35.6)$ & $2755(30.5)$ & $2732(42.3)$ & $190(34.1)$ & $<0.001$ \\
\hline Antipsychotics & $4389(26.6)$ & $2226(24.6)$ & $1940(30.0)$ & $135(24.2)$ & $<0.001$ \\
\hline Antiepileptic & $1153(7.0)$ & $527(5.8)$ & $469(7.3)$ & $96(17.2)$ & $<0.001$ \\
\hline Previous antidepressant use, $n(\%)$ & $4095(24.8)$ & $2164(23.9)$ & $1601(24.8)$ & $185(33.2)$ & $<0.001$ \\
\hline
\end{tabular}

$C O P D$, chronic obstructive pulmonary disease; $A C h E I$, acetylcholinesterase inhibitor; NSAIDs, nonsteroidal anti-inflammatory drugs; BZDR, benzodiazepines and related drugs.* Comparison between antidepressant groups with chi squared tests

within 6 months, $31.1 \%$ had discontinued antidepressant use, $40.8 \%$ after 1 year, $54.6 \%$ after 2 years, and $64.1 \%$ after 3 years. Continuation of use by drug groups are presented in Fig. 1b. Within 6 months, $25.7 \%$ of SSRI users, $37.5 \%$ of mirtazapine users, and $43.4 \%$ of SNRI users had discontinued their antidepressant use. Median time to discontinuation was 732 days for SSRI users, 439 days for mirtazapine users, and 288 days for SNRI users (Table 2).
Factors associated with discontinuation of antidepressant use were age over 85 , male gender, diabetes, use of memantine, opioids, and antiepileptics (Table 3). Use of BZDR and antipsychotics had inverse association with discontinuation. When analyzing the impact of the drug groups, mirtazapine (HR 1.33; 95\% CI 1.27-1.39) and SNRIs (HR 1.61; 95\% CI 1.44-1.80) were associated with earlier discontinuation compared with SSRI use in the unadjusted analyses. After adjusting for 
Table 2 Comparison of the durations of the first antidepressant use periods and reasons for the end of use periods between antidepressant groups (selective serotonin reuptake inhibitors [SSRI], mirtazapine and serotonin and norepinephrine reuptake inhibitor [SNRI] users)

\begin{tabular}{|c|c|c|c|c|c|}
\hline & New users $n=16,501$ & SSRI $n=9047$ & Mirtazapine $n=6462$ & SNRI $n=557$ & $p$ value* \\
\hline \multicolumn{5}{|c|}{ Duration of the first antidepressant use period, $n(\%)$} & $<0.001$ \\
\hline Median (IQR days) & $309(93-830)$ & $331(101-829)$ & $202(52-635)$ & $134(37-522)$ & \\
\hline$<1$ month & $2247(13.6)$ & $889(9.8)$ & $1311(20.3)$ & $125(22.4)$ & \\
\hline $1-6$ months & $4306(26.1)$ & $2476(27.4)$ & $1798(27.8)$ & $190(34.1)$ & \\
\hline $6-12$ months & $2352(14.3)$ & $1391(15.4)$ & $943(14.6)$ & $65(11.7)$ & \\
\hline $1-2$ years & $2882(17.5)$ & $1720(19.0)$ & $992(15.4)$ & $82(14.7)$ & \\
\hline $2-3$ years & $1779(10.8)$ & $1013(11.2)$ & $566(8.8)$ & $31(5.6)$ & \\
\hline $3-4$ years & $1156(7.0)$ & $640(7.1)$ & $372(5.8)$ & $37(6.6)$ & \\
\hline Over 4 years & $1779(10.8)$ & $918(10.1)$ & $480(7.4)$ & $27(4.8)$ & \\
\hline \multicolumn{5}{|c|}{ Reasons for end of the first period, $n(\%)$} & $<0.001$ \\
\hline Discontinuation & 9167 (55.6) & 4479 (49.5) & $3598(55.7)$ & $326(58.5)$ & \\
\hline Death & $2339(14.2)$ & $1172(13.0)$ & $825(12.8)$ & $60(10.8)$ & \\
\hline End of study period & $1402(8.5)$ & $638(7.1)$ & $558(8.6)$ & $39(7.0)$ & \\
\hline Long hospital stays & $1814(11.0)$ & $1060(11.7)$ & $522(8.1)$ & $49(8.8)$ & \\
\hline Switch/concomitant use & NA & $780(8.6)$ & $479(7.4)$ & $56(10.1)$ & \\
\hline Continued use over 4 years & $1779(10.8)$ & $918(10.1)$ & $480(7.4)$ & $27(4.8)$ & \\
\hline \multicolumn{5}{|l|}{ Time to discontinuation, days } & $<0.001$ \\
\hline Median (95\% CI) & $588(564-612)$ & $732(696-768)$ & $439(404-474)$ & $288(191-385)$ & \\
\hline
\end{tabular}

$S S R I$, selective serotonin reuptake inhibitor; $S N R I$, serotonin and norepinephrine reuptake inhibitor; $I Q R$, interquartile range; $N A$, not applicable; $C I$, confidence interval. Comparison between antidepressant groups with chi squared tests

comorbid conditions and concomitant medications, the results remained significant for mirtazapine (HR 1.35; 95\% CI 1.291.41) and SNRIs (HR 1.59; 95\% CI 1.42-1.79).

\section{Discussion}

To our knowledge, this is the first study focusing on the duration of antidepressant use among community-dwelling persons with AD. We found that median duration of use was 309 days and median time to discontinuation was even longer, 588 days. Previous studies have focused on general older population like a German study among people aged $>65$ that reported a median duration of only 64 days [17]. A previous study among Australian veteran population aged 55 years or more found that median duration of the first antidepressant use was 175 days [15]. These findings on duration of use are much shorter than in our study. However, comparisons to our findings is difficult due to different methods used to estimate duration of antidepressant use in these studies, and varying study populations.

In general, indications for antidepressant use include depression and anxiety disorders, and some of them may be effective also for neuropathic pain [22, 23]. Among people with AD, antidepressants may be used for BPSD such as anxiety, depressive symptoms, and agitation $[6,24]$. In our study within 6 months, $31 \%$ of the antidepressant users had discontinued antidepressant use. That is less than in a previous study among older persons with dementia, where $53 \%$ of antidepressant users had discontinued within 6 months [18]. In Australian veteran population, $50 \%$ also discontinued antidepressant use within 6 months [15].

In accordance with the previous study among persons with dementia, we found that discontinuation was more common among the oldest persons [18]. It might be that the oldest persons are monitored more carefully. The oldest persons may have higher risk for adverse effects and events associated with antidepressant use, even at lower doses, due to aging-related changes in pharmacokinetics and pharmacodynamics [25] and for this reason, the threshold for discontinuation may be lower. Also, we found that male gender was associated with shorter antidepressant use which is in line with the previous Australian study [15]. In the Australian study, $57 \%$ of participants were male and only $6 \%$ had dementia which may explain shorter durations of use compared with our study. They also found that dementia was associated with longer duration of use. Finnish clinical care guidelines for BPSDs suggests that need for antidepressant use should be evaluated every three to 6 months, as some BPSD symptoms can resolve by itself [24]. Due to a risk of adverse events such as falls [26], fractures, all-cause mortality, and upper gastrointestinal bleeding [8] and modest efficacy for BPSD [6, 7], duration of antidepressant use should be limited when treating BPSD. Antidepressant use should be discontinued if there is no more current indication for use, due to lack of benefit, and at emergence of adverse effects or events. 
Fig. 1 Time to discontinuation of first antidepressant use. a Any antidepressant use. b By the antidepressant group a

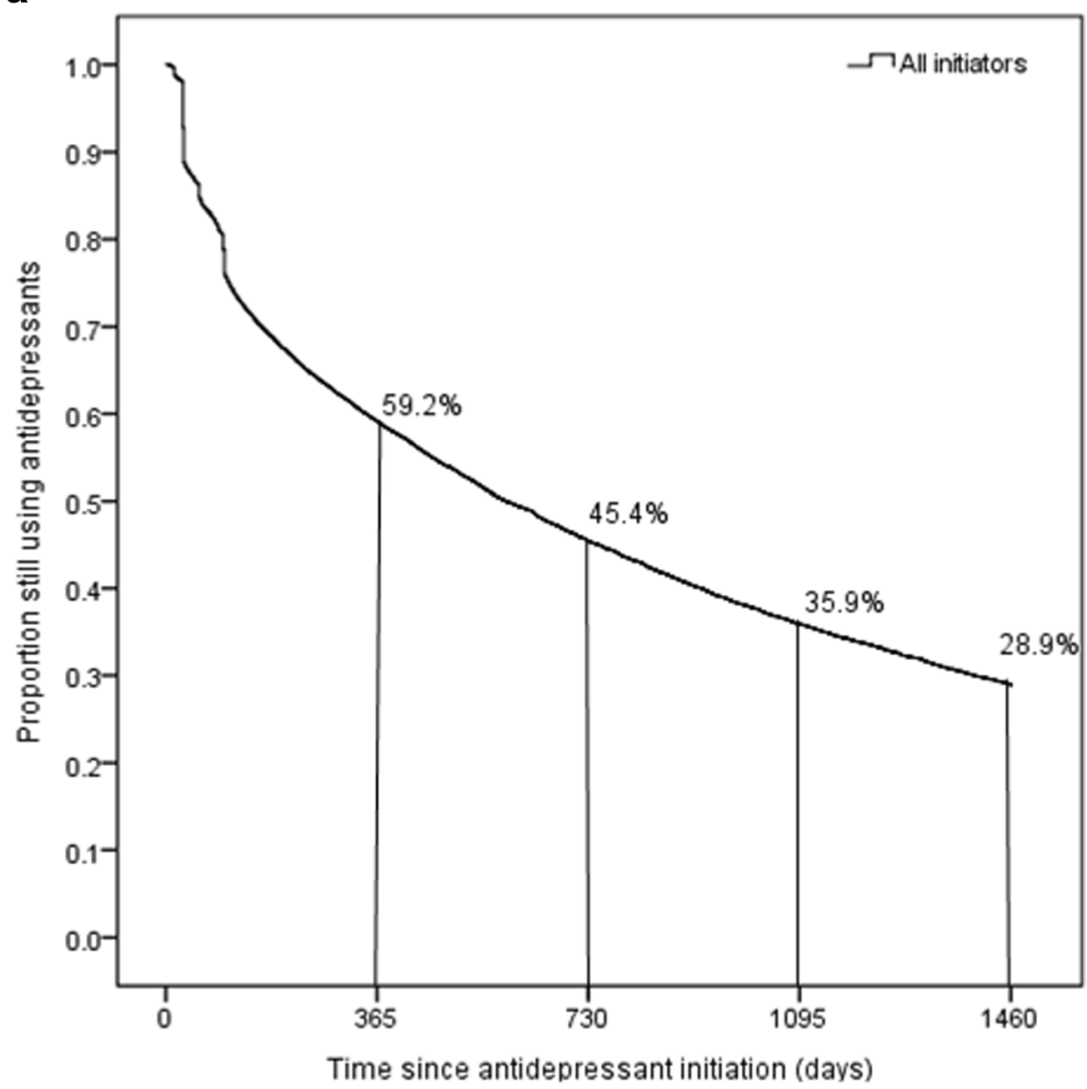

b

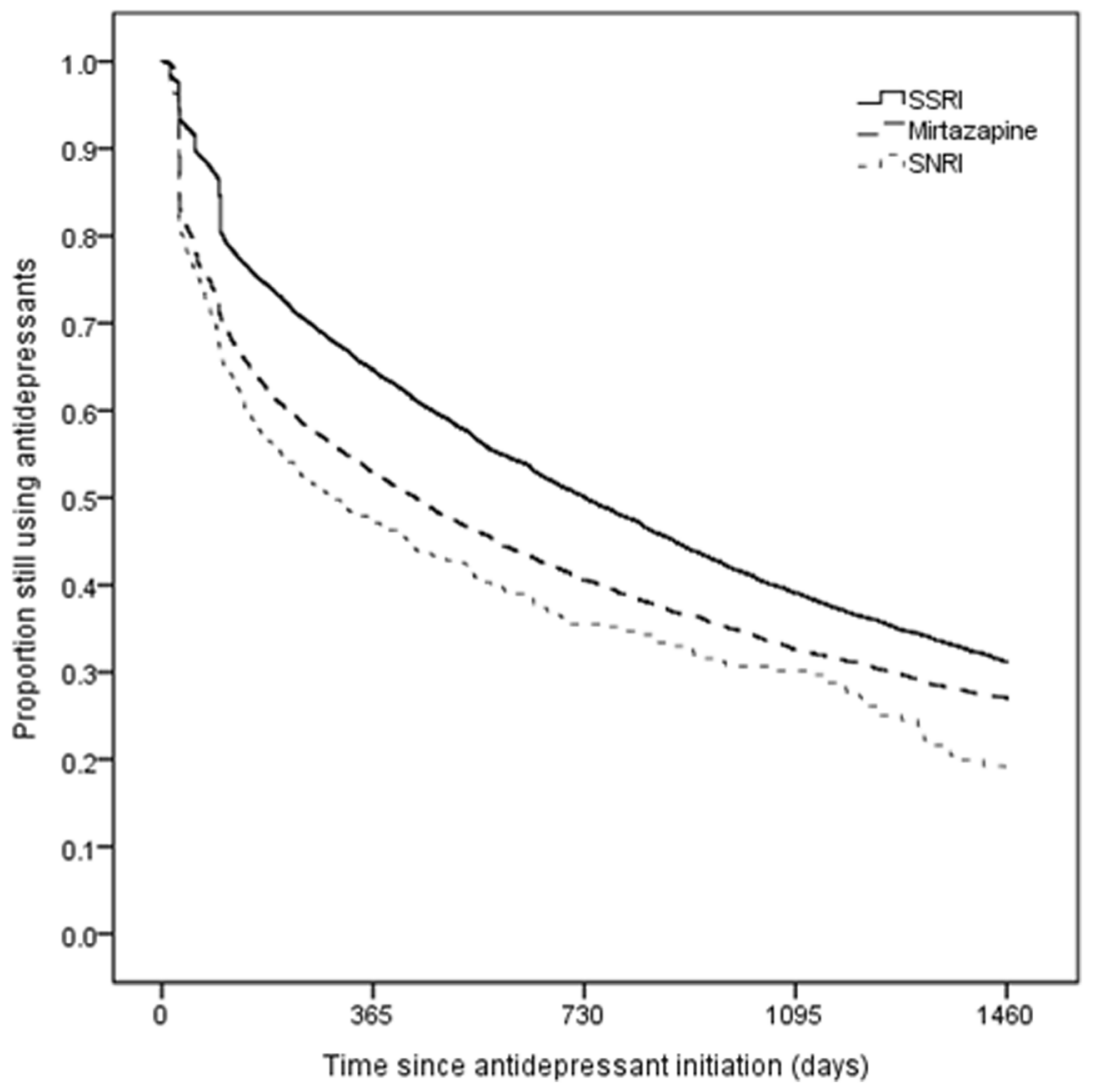


Another reason for the longer duration of use in our study compared with the previous studies can be use of different antidepressants. In the study among persons with dementia [18], 54.4\% used TCAs and $45.6 \%$ used SSRI/ SNRI whereas in our study, TCAs were used only by $1.4 \%$ and $54.8 \%$ used SSRIs. In the Australian study, TCAs were excluded and thus, their results describe use of newer antidepressants [15]. Both the Finnish guidelines [24] and American Psychiatric Association (APA) [27] recommend that SSRIs may be preferred for BPSD symptoms due to more favorable adverse effect profile compared to TCAs. Thus, our results follow these guidelines of care in terms of avoiding TCA use.
In our study, SSRIs were used for longer time periods than mirtazapine and SNRIs. The longer duration of use has been associated with SSRI use also in the previous studies although the reference antidepressant drug group has varied in these studies $[15,17,18]$. Higher risk of treatment discontinuation with mirtazapine compared with SSRIs may be explained by different indications of use. Mirtazapine may be used for insomnia [28] and treatment durations may be shorter for sleep disturbances than for other symptoms, including depressive symptoms. However, there is a lack of evidence on efficacy of mirtazapine use for sleep disorders among communitydwelling AD patients. A pilot study did not find a

Table 3 Factors associated with discontinuation of antidepressant use in unadjusted and adjusted Cox proportional hazard models, presented with hazard ratios (HRs) with 95\% confidence intervals (CIs) and corresponding $p$ values. All factors listed were included in the adjusted model

\begin{tabular}{|c|c|c|c|c|}
\hline Covariates & Unadjusted HR (95\% CI) & $p$ value & Adjusted HR (95\% CI) & $p$ value \\
\hline Male & $1.09(1.04-1.14)$ & $<0.001$ & $1.10(1.05-1.15)$ & $<0.001$ \\
\hline \multicolumn{5}{|l|}{ Age at the time of initiation } \\
\hline$<75$ & 1 (reference) & & & \\
\hline $75-84$ & $1.01(0.96-1.07)$ & 0.642 & $1.01(0.96-1.08)$ & 0.642 \\
\hline$\geq 85$ & $1.12(1.05-1.19)$ & $<0.001$ & $1.12(1.05-1.20)$ & $<0.001$ \\
\hline \multicolumn{5}{|l|}{ Comorbidities } \\
\hline Cardiovascular disease & $1.06(1.02-1.10)$ & 0.007 & $1.05(1.00-1.09)$ & 0.040 \\
\hline History of stroke & $0.98(0.91-1.04)$ & 0.474 & $0.95(0.88-1.02)$ & 0.120 \\
\hline Diabetes & $1.10(1.04-1.17)$ & 0.002 & $1.08(1.02-1.15)$ & 0.011 \\
\hline Asthma/COPD & $1.03(0.96-1.10)$ & 0.455 & $1.02(0.95-1.02)$ & 0.565 \\
\hline Glaucoma & $0.98(0.92-1.06)$ & 0.653 & $0.98(0.91-1.05)$ & 0.515 \\
\hline Active cancer & $0.98(0.88-1.10)$ & 0.738 & $0.95(0.85-1.06)$ & 0.338 \\
\hline Rheumatoid arthritis & $1.07(0.97-1.18)$ & 0.204 & $1.08(0.98-1.20)$ & 0.118 \\
\hline Epilepsy & $1.01(0.87-1.16)$ & 0.948 & $0.91(0.78-1.07)$ & 0.249 \\
\hline History of schizophrenia & $0.88(0.72-1.07)$ & 0.187 & $0.96(0.78-1.17)$ & 0.677 \\
\hline History of depression or bipolar disorder & $0.88(0.77-1.01)$ & 0.063 & $0.91(0.80-1.05)$ & 0.200 \\
\hline Previous fracture & $0.99(0.94-1.04)$ & 0.590 & $0.99(0.94-1.04)$ & 0.605 \\
\hline Substance abuse & $0.89(0.78-1.01)$ & 0.075 & $0.90(0.79-1.03)$ & 0.129 \\
\hline \multicolumn{5}{|c|}{ Use of other drugs 6 months before antidepressant initiating } \\
\hline \multicolumn{5}{|l|}{ Alzheimer's disease medication } \\
\hline AChEI & $1.03(0.99-1.08)$ & 0.198 & $1.02(0.98-1.07)$ & 0.336 \\
\hline Memantine & $1.15(1.10-1.19)$ & $<0.001$ & $1.14(1.09-1.19)$ & $<0.001$ \\
\hline \multicolumn{5}{|l|}{ Analgesics } \\
\hline Opioids & $1.11(1.04-1.18)$ & 0.002 & $1.10(1.03-1.17)$ & 0.008 \\
\hline NSAIDs & $0.93(0.88-0.99)$ & 0.024 & $0.94(0.88-1.00)$ & 0.045 \\
\hline Paracetamol & $1.03(0.99-1.08)$ & 0.175 & $1.01(0.96-1.05)$ & 0.838 \\
\hline \multicolumn{5}{|l|}{ Psychotropic drugs } \\
\hline BZDR & $0.93(0.89-0.97)$ & $<0.001$ & $0.93(0.89-0.97)$ & 0.002 \\
\hline Antipsychotics & $0.96(0.91-1.00)$ & 0.063 & $0.94(0.90-0.99)$ & 0.019 \\
\hline Antiepileptic & $1.13(1.04-1.22)$ & 0.003 & $1.15(1.06-1.26)$ & 0.001 \\
\hline Previous antidepressant use & $0.97(0.92-1.01)$ & 0.159 & $0.99(0.94-1.04)$ & 0.708 \\
\hline
\end{tabular}

$C O P D$, chronic obstructive pulmonary disease; $A C h E I$, acetylcholinesterase inhibitor; NSAIDs, nonsteroidal anti-inflammatory drugs; $B Z D R$, benzodiazepines and related drugs 
significant improvement with sleep disorders when using $15 \mathrm{mg}$ of mirtazapine daily [29]. In turn, according to Finnish care guidelines, mirtazapine should be used with 3.75-7.5 mg dosage for sleep disorders [30].

SNRI users were more likely to use analgesics and antiepileptics and had more often rheumatoid arthritis and previous fracture compared to the other groups. It might be that SNRIs are more often used for neuropathic pain. SNRIs, like duloxetine, and antiepileptics are among the first-line medications for neuropathic pain [23]. Use of opioids and antiepileptics was associated with earlier discontinuation of antidepressant use, reflecting difficulties in treating neuropathic pain.

Use of BZDRs and antipsychotics were associated with longer durations of antidepressant use. These drugs are often used for the treatment for BPSD [31], and thus, these associations may imply the presence of more severe BPSD symptoms. Previous study among people aged 55 or more found longer antidepressant treatments for those with psychiatric disorders and higher risk of discontinuation in persons with cancer and multi-morbidities [15]. In our study, discontinuation of use was not associated with somatic or mental diseases except for diabetes. On the contrary, memantine use was associated with discontinuation of antidepressant use. Memantine use could be a marker of more advanced stage of $\mathrm{AD}$ as it is indicated for treatment of moderate and severe AD. Memantine is also used in treatment of BPSD symptoms and previous studies have linked memantine use to more frequent use of psychotropic drugs [32]. However, memantine initiation has also been associated with a decrease or stabilization in the prevalence of antidepressant use [32, 33]. Memantine is somewhat efficacious for BPSD symptoms, such as delusions and agitation/ aggression [34] whereas the results on the impact on depressive symptoms are controversial $[34,35]$.

This study was a nationwide cohort including the all community-dwelling persons with AD. Register-based data enabled long-term follow-up of these persons. Antidepressant drug purchases were identified from dispensed, reimbursed purchases without any recall bias. In addition, the PRE2DUP method estimates well antidepressant use among older persons $[36,37]$. A limitation of this study was a lack of data on indications for antidepressant use. Data did not include severity of $\mathrm{AD}$ or frequency or severity of BPSD. Our results are not generalizable to persons with $\mathrm{AD}$ living in the nursing homes or long-term care facilities as we did not have data on drug use in these institutions. We censored the follow-up when person was admitted to long-term hospital/institutional care.

\section{Conclusion}

Antidepressants are often used long-term among communitydwelling persons with AD. SSRIs are used for longer periods than mirtazapine or SNRIs. Need of antidepressant treatment in persons with $\mathrm{AD}$ should be evaluated regularly due to insufficient evidence of efficacy and increased risk for adverse events such as falls and related fractures.

Acknowledgements Open access funding provided by University of Eastern Finland (UEF) including Kuopio University Hospital.

\section{Compliance with ethical standards}

According to Finnish legislation, no ethics committee approval is required as only register-based data was used and participants were not contacted in any way.

Conflict of interest HT, JT, and AT have participated in research projects funded by Janssen and Eli Lilly with grants paid to the institution where they were employed. AT is a member of Janssen advisory board. JT has served as a consultant to Lundbeck, Organon, Janssen-Cilag, Eli Lilly, AstraZeneca, F. Hoffman-La Roche, and Bristol-Myers Squibb. He has received fees for giving expert opinions to Bristol-Myers Squibb and GlaxoSmithKline; lecture fees from Janssen-Cilag, Bristol-Myers Squibb, Eli Lilly, Pfizer, Lundbeck, GlaxoSmithKline, AstraZeneca, and Novartis; and grant from Stanley Foundation. JT is a member of advisory board in AstraZeneca, Janssen-Cilag, and Otsuka. MK has received personal research grant from $\mathrm{Oy} \mathrm{H}$. Lundbeck $\mathrm{Ab}$ foundation outside the submitted work. Other authors declare no conflicts of interest.

Open Access This article is distributed under the terms of the Creative Commons Attribution 4.0 International License (http:// creativecommons.org/licenses/by/4.0/), which permits unrestricted use, distribution, and reproduction in any medium, provided you give appropriate credit to the original author(s) and the source, provide a link to the Creative Commons license, and indicate if changes were made.

\section{References}

1. Mars B, Heron J, Kessler D, Davies NM, Martin RM, Thomas KH, Gunnell D (2017) Influences on antidepressant prescribing trends in the UK: 1995-2011. Soc Psychiatry Psychiatr Epidemiol 52:193200. https://doi.org/10.1007/s00127-016-1306-4

2. Taipale H, Koponen M, Tanskanen A, Tolppanen AM, Tiihonen J, Hartikainen S (2014) High prevalence of psychotropic drug use among persons with and without Alzheimer [U+05F3] s disease in Finnish nationwide cohort. Eur Neuropsychopharmacol 24: 1729-1737. https://doi.org/10.1016/j.euroneuro.2014.10.004

3. Laitinen M-L, Lönnroos E, Bell JS, Lavikainen P, Sulkava R, Hartikainen S (2015) Use of antidepressants among communitydwelling persons with Alzheimer's disease: a nationwide registerbased study. Int Psychogeriatr 27:669-672. https://doi.org/10.1017/ S1041610214002427

4. David R, Manera V, Fabre R, Pradier C, Robert P, Tifratene K (2016) Evolution of the antidepressant prescribing in Alzheimer's disease and related disorders between 2010 and 2014: results from the French National Database on Alzheimer's disease (BNA). J Alzheimers Dis 53:1365-1373. https://doi.org/10.3233/JAD-160238

5. Wong J, Motulsky A, Abrahamowicz M et al (2017) Off-label indications for antidepressants in primary care: descriptive study of prescriptions from an indication based electronic prescribing system. BMJ 356:j603. https://doi.org/10.1136/bmj.j603

6. Seitz D, Adunuri N, Gill S, Al E (2011) Antidepressants for agitation and psychosis in dementia. Cochrane Database Syst Rev 16: CD008191 
7. Orgeta V, Tabet N, Nilforooshan R, Howard R (2017) Efficacy of antidepressants for depression in Alzheimer's disease: systematic review and meta-analysis. J Alzheimers Dis 58:725-733. https:// doi.org/10.3233/JAD-161247

8. Coupland C, Dhiman P, Morriss R, Arthur A, Barton G, HippisleyCox J (2011) Antidepressant use and risk of adverse outcomes in older people: population based cohort study. Bmj 343:d4551. https://doi.org/10.1136/bmj.d4551

9. Maslej MM, Bolker BM, Russell MJ, Eaton K, Durisko Z, Hollon SD, Swanson GM, Thomson Jr JA, Mulsant BH, Andrews PW (2017) The mortality and myocardial effects of antidepressants are moderated by preexisting cardiovascular disease: a meta-analysis. Psychother Psychosom 86:268-282. https://doi.org/10.1159/000477940

10. Spina E, Trifirò G, Caraci F (2012) Clinically significant drug interactions with newer antidepressants. CNS Drugs 26:39-67. https://doi.org/10.2165/11594710-000000000-00000

11. Taipale H, Koponen M, Tanskanen A et al (2017) Risk of head and traumatic brain injuries associated with antidepressant use among community-dwelling persons with Alzheimer's disease: a nationwide matched cohort study. Alzheimer's Res Ther:9. https://doi.org/ 10.1186/s13195-017-0285-3

12. Torvinen-Kiiskinen S, Tolppanen A-M, Koponen M, Tanskanen A, Tiihonen J, Hartikainen S, Taipale H (2017) Antidepressant use and risk of hip fractures among community-dwelling persons with and without Alzheimer's disease. Int J Geriatr Psychiatry 32:e107e115. https://doi.org/10.1002/gps.4667

13. Porsteinsson AP, Drye LT, Pollock BG, Devanand DP, Frangakis C, Ismail Z, Marano C, Meinert CL, Mintzer JE, Munro CA, Pelton G, Rabins PV, Rosenberg PB, Schneider LS, Shade DM, Weintraub D, Yesavage J, Lyketsos CG, CitAD Research Group (2014) Effect of citalopram on agitation in Alzheimer disease: the CitAD randomized clinical trial. JAMA 311:682-691. https://doi.org/10.1001/jama.2014.93

14. Fava GA, Benasi G, Lucente M, Offidani E, Cosci F, Guidi J (2018) Withdrawal symptoms after serotonin-noradrenaline reuptake inhibitor discontinuation: systematic review. Psychother Psychosom 87:195-203. https://doi.org/10.1159/000491524

15. Lu CY, Roughead E (2012) New users of antidepressant medications: first episode duration and predictors of discontinuation. Eur J Clin Pharmacol 68:65-71. https://doi.org/10.1007/s00228-011-1087-3

16. Braunstein D, Hardy A, Boucherie Q, Frauger E, Blin O, Gentile G, Micallef J (2017) Antidepressant adherence patterns in older patients: use of a clustering method on a prescription database. Fundam Clin Pharmacol 31:226-236. https://doi.org/10.1111/fcp.12252

17. Jobski K, Schmedt N, Kollhorst B, Krappweis J, Schink T, Garbe E (2017) Characteristics and drug use patterns of older antidepressant initiators in Germany. Eur J Clin Pharmacol 73:105-113. https:// doi.org/10.1007/s00228-016-2145-7

18. Booker A, Bohlken J, Rapp MA, Kostev K (2016) Persistence with antidepressant drugs in patients with dementia: a retrospective database analysis. Int J Clin Pharmacol Ther 54:323-329. https://doi. org/10.5414/CP202572

19. Tolppanen A-M, Taipale H, Koponen M, Lavikainen P, Tanskanen A, Tiihonen J, Hartikainen S (2016) Cohort profile: the Finnish medication and Alzheimer's disease (MEDALZ) study. BMJ Open 6:e012100. https://doi.org/10.1136/bmjopen-2016-012100

20. McKhann G, Drachman D, Folstein M, Katzman R, Price D, Stadlan EM (1984) Clinical diagnosis of Alzheimer's disease: report of the NINCDS-ADRDA work group under the auspices of Department of Health and Human Services Task Force on Alzheimer's disease. Neurology 34:939-944

21. Tanskanen A, Taipale H, Koponen M, Tolppanen AM, Hartikainen S, Ahonen R, Tiihonen J (2015) From prescription drug purchases to drug use periods - a second generation method (PRE2DUP). BMC Med Inform Decis Mak 15:21. https://doi.org/10.1186/s12911-015-0140-z
22. Ables AZ, Baughman OL (2003) Antidepressants: update on new agents and indications. Am Fam Physician 67:547-554

23. Finnerup NB, Attal N, Haroutounian S, McNicol E, Baron R, Dworkin RH, Gilron I, Haanpää M, Hansson P, Jensen TS, Kamerman PR, Lund K, Moore A, Raja SN, Rice ASC, Rowbotham M, Sena E, Siddall P, Smith BH, Wallace M (2015) Pharmacotherapy for neuropathic pain in adults: a systematic review and meta-analysis. Lancet Neurol 14:162173. https://doi.org/10.1016/S1474-4422(14)70251-0

24. Finnish Medical Society Duodecim. Memory disorders: Current Care Guidelines (in Finnish with English abstract). The Finnish Medical Society Duodecim. Available at: www.kaypahoito.fi Accessed 29 March 2018

25. Sultana J, Spina E, Trifirò G (2015) Antidepressant use in the elderly: the role of pharmacodynamics and pharmacokinetics in drug safety. Expert Opin Drug Metab Toxicol 11:883-892. https://doi. org/10.1517/17425255.2015.1021684

26. Seppala LJ, Wermelink AM, de Vries M et al (2018) Fall-riskincreasing drugs: a systematic review and meta-analysis: II. Psychotropics. J Am Med Dir Assoc. https://doi.org/10.1016/j. jamda.2017.12.013

27. APA Work Group on Alzheimer's Disease and other Dementias, Rabins P, Blacker D et al (2007) American psychiatric association practice guideline for the treatment of patients with Alzheimer's disease and other dementias. Second edition. Am J Psychiatry 164(suppl):5-56

28. Alam A, Voronovich Z, Carley JA (2013) A review of therapeutic uses of mirtazapine in psychiatric and medical conditions. Prim Care Companion CNS disord 15(5):24511451

29. Scoralick FM, Louzada LL, Quintas JL, Naves JOS, Camargos EF, Nóbrega OT (2017) Mirtazapine does not improve sleep disorders in Alzheimer's disease: results from a double-blind, placebocontrolled pilot study. Psychogeriatrics 17:89-96. https://doi.org/ 10.1111/psyg.12191

30. Duodecim FMS (2016) Current care: sleep disorders. http://www. kaypahoito.fi. Accessed 13 May 2018

31. Preuss UW, Wong J, Koller G (2016) Treatment of behavioral and psychological symptoms of dementia: a systematic review. Psychiatr Pol 50:679-715. https://doi.org/10.12740/PP/64477

32. Martinez C, Jones RW, Rietbrock S (2013) Trends in the prevalence of antipsychotic drug use among patients with Alzheimer's disease and other dementias including those treated with antidementia drugs in the community in the UK: a cohort study. BMJ Open 3. https://doi.org/10.1136/bmjopen-2012-002080

33. Vidal J-S, Lacombe J-M, Dartigues J-F et al (2008) Evaluation of the impact of memantine treatment initiation on psychotropics use: a study from the French national health care database. Neuroepidemiology 31 : 193-200. https://doi.org/10.1159/000158226

34. Gauthier $\mathrm{S}$, Loft H, Cummings J (2008) Improvement in behavioral symptoms in patients with moderate to severe Alzheimer's disease by memantine: a pooled data analysis. Int J Geriatr Psychiatry 23: 537-545. https://doi.org/10.1002/gps

35. Amidfar M, Khiabany M, Kohi A, Salardini E, Arbabi M, Roohi Azizi M, Zarrindast MR, Mohammadinejad P, Zeinoddini A, Akhondzadeh S (2017) Effect of memantine combination therapy on symptoms in patients with moderate-to-severe depressive disorder: randomized, double-blind, placebo-controlled study. J Clin Pharm Ther 42:44-50. https://doi.org/10.1111/jcpt.12469

36. Taipale H, Tanskanen A, Koponen M, Tolppanen AM, Tiihonen J, Hartikainen S (2016) Agreement between PRE2DUP register data modeling method and comprehensive drug use interview among older persons. Clin Epidemiol 8:363-371. https://doi.org/10.2147/ CLEP.S116160

37. Tanskanen A, Taipale H, Koponen M, Tolppanen AM, Hartikainen S, Ahonen R, Tiihonen J (2017) Drug exposure in register-based research -an expert-opinion based evaluation of methods. PLoS One 12:e184070 